Article

\title{
Quantitative Analysis of Soil Displacement Induced by Ground Loss and Shield Machine Mechanical Effect in Metro Tunnel Construction
}

\author{
Yimo Zhu ${ }^{1}$, Liang Chen ${ }^{2, *}$, Heng Zhang ${ }^{1, *}$, Peng $\mathrm{Tu}^{3}$ and Shougen Chen ${ }^{1}$ \\ 1 Key Laboratory of Transportation Tunnel Engineering, Ministry of Education, Southwest Jiaotong University, \\ Chengdu 610031, China \\ 2 School of Civil Engineering, Changsha University of Science and Technology, Changsha 410076, China \\ 3 Sichuan Vocational and Technical College of Communications, Chengdu 611130, China \\ * Correspondence: liangchen_2018@163.com (L.C.); Hengzhang1985@outlook.com (H.Z.)
}

Received: 26 June 2019; Accepted: 24 July 2019; Published: 26 July 2019

check for updates

\begin{abstract}
In order to relieve the increasing ground traffic pressure in the process of urbanization in China, it is inevitable to build more metro lines. However, the stratum movement caused by tunneling affects the safety of adjacent underground structures and aboveground buildings. Therefore, how to evaluate and control the stratum movement is a prominent problem. In this paper, based on the engineering project of an interval tunnel between Shizishan Station and Chuanshi Station in Chengdu Metro Line 7, China, the action mechanism of stratum movement induced by shield tunneling is analyzed, and the effect factors are divided into two categories: ground loss factors and mechanical factors. Combining the advantages of Loganathan method and mirror source-sink method, a new solution of three-dimensional displacement induced by ground loss is proposed. Based on the elastic half-space Mindlin model, the displacement at any point induced by four mechanical effect factors is deduced. Finally, the total displacement is verified by field monitoring data and quantitative analyzed in various parts.
\end{abstract}

Keywords: metro constructions; shield tunnel; ground settlement; soil displacement; analytical; Mindlin solution

\section{Introduction}

With the acceleration of urbanization in China, the growth rate of urban land use is much lower than the urban population growth rate. The limited number of urban surface land resources can no longer meet people's needs for living space. The development direction of urban space is gradually changing from the horizontal direction of extension to the vertical direction of intension, which has resulted in many underground structures [1-4]. Although the development of urban underground space has detailed plans and arrangements before construction, it still has some unpredictability in the long term. Therefore, the negative conditions that new underground structures create near the existing ones happen from time to time. As the main artery of underground traffic in modern cities, this phenomenon of metro tunnels is particularly prominent. Among many construction methods of metro tunnel, shield tunneling is becoming the preferred construction scheme because of its advantages of fast construction and small disturbance to stratum [5-9]. Although shield tunneling has many advantages as mentioned above, and the construction technology has made great progress in many years, due to the defects of geological conditions and construction technology, the advance of shield tunneling will inevitably create a disturbance, change the stress state of soil and cause stratum displacement. Therefore, how to evaluate and control the stratum displacement has always been a concern for engineers [10-12]. 
The important of this problem has prompted researchers to study many methods for predicting stratum displacement induced by shield tunneling. Based on the factors affecting stratum displacement, the methods can be divided into two categories. The first category concerns the ground loss factors during shield excavation, and the second addresses the mechanical effect factors. In terms of ground loss factors, empirical solution is one of the most commonly used methods. Peck assumed that the curve of land settlement trough satisfies the conditions of Gauss distribution and invariant stratum volume, as was deduced Peck's empirical formula based on field monitoring data [13]. Celestino et al. [14] and many other researchers [15-19] noted that Peck's empirical formula cannot accurately describe soil settlement trough in many cases and proposed improved empirical formulas under different geologic conditions. Besides empirical solution, there are also many researchers who contribute significantly through analytical solution [20-23], numerical simulation [24-26] and model testing [27,28]. In terms of mechanical effect factors, Mindlin's solution is one of the well-known solutions to calculate the stress and displacement caused by a point load at an embedment depth in an elastic half-space [29]. Based on Mindlin's solution, many modified analytical solutions are proposed [30-33]. For instance, Verruijt et al. derived a theoretical solution for the deformations of an elastic half-plane with a circular cavity, which is often used in tunnel excavation. [34,35].

However, most previous studies only consider the stratum displacement caused by ground loss factors, ignoring the influence of mechanical factors without clear theoretical basis $[7,8,17,21]$. A few studies containing mechanical factors are not thorough enough, and they are usually shown in the form of total displacement without the quantitative analysis of the proportion of stratum displacement caused by each factor $[6,9,10]$. In this paper, based on the engineering project of an interval tunnel between Shizishan Station and Chuanshi Station in Chengdu Metro Line 7, China, combining Loganathan empirical formula and mirror source-sink method, the stratum displacement caused by ground loss factors is calculated. The mechanical effect factors are divided into four parts and calculated based on the Mindlin solution. The proportion of stratum displacement caused by each factor is quantitatively analyzed, which can provide guidance for the stratum displacement calculation of shield tunneling in the future.

\section{Engineering Background}

The engineering project in this paper is an interval tunnel between Shizishan Station and Chuanshi Station in Chengdu Metro Line 7, China. The tunnel consists of two single-track tunnels with a total length of $970.4 \mathrm{~m}$ and a burial depth of $15 \mathrm{~m}$, which is mainly located in weathered mudstone stratum and excavated by EPB (Earth Pressure Balanced) shield. The external diameter of shield and fabricated precast segment are $6 \mathrm{~m}$ and $6.28 \mathrm{~m}$, respectively. The diagram of shield tunneling in diagram is shown in Figure 1.

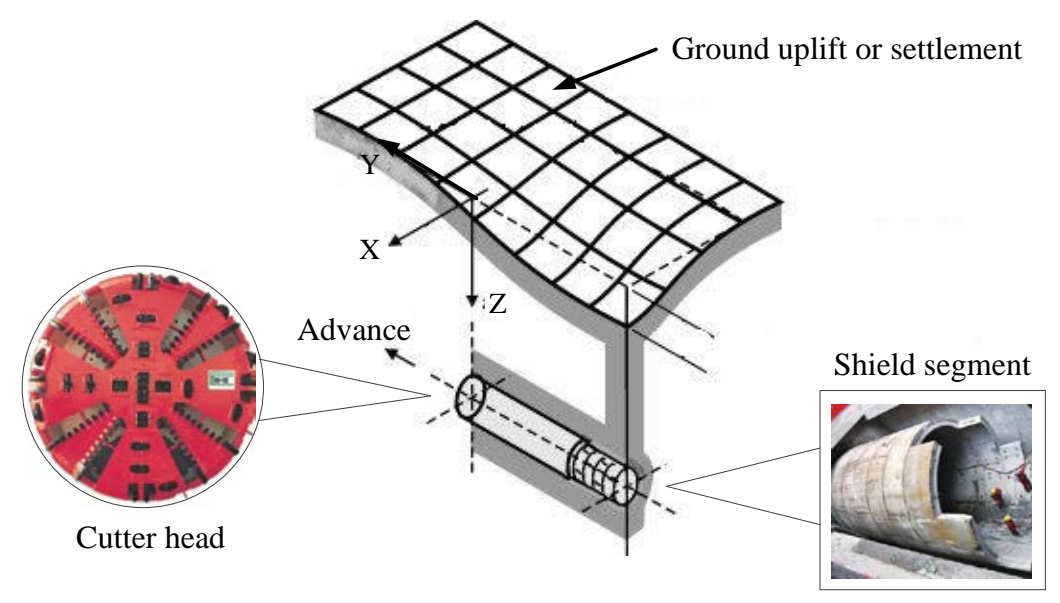

Figure 1. The diagram of shield tunneling in stratum. 
In order to carry out the calculations, the parameters that need to be determined can be divided into two categories. The first category concerns the physical parameters of soil, such as elastic modules, Poisson's ratio, etc. They are obtained from engineering geological reports and field experiments, as shown in Table 1. The second is the construction parameters of the shield machine, such as shield tunneling speed, strain rate of grouting layer, etc. The equipment used in this project is CREC153 EPB shield machine produced by China Railway Engineering Equipment Group, its parameters are shown in Table 2.

Table 1. Physical parameters of soil.

\begin{tabular}{ccccccc}
\hline Material & $\begin{array}{c}\text { Unit Weight } \\
\left(\mathbf{k N} / \mathbf{m}^{\mathbf{3}}\right)\end{array}$ & $\begin{array}{c}\text { Thickness } \\
\mathbf{( m )}\end{array}$ & $\begin{array}{c}\text { Poisson's } \\
\text { Ratio }\end{array}$ & $\begin{array}{c}\text { Cohesion } \\
\mathbf{( k P a )}\end{array}$ & $\begin{array}{c}\text { Friction } \\
\text { Angle }\end{array}$ & $\begin{array}{c}\text { Elastic Modules } \\
\mathbf{( M P a})\end{array}$ \\
\hline Topsoil & 20 & 2.1 & 0.3 & 45 & $14^{\circ}$ & 5.94 \\
\hline $\begin{array}{c}\text { Intermediary } \\
\text { weathered mudstone }\end{array}$ & 23.4 & 37.9 & 0.17 & 300 & $18^{\circ}$ & 180 \\
\hline
\end{tabular}

Table 2. Construction parameters of shield machine.

\begin{tabular}{cccccc}
\hline Parameter & $\begin{array}{c}\text { Shield Tunneling } \\
\text { Speed (mm/min) }\end{array}$ & $\begin{array}{c}\text { Rotation Speed of } \\
\text { Cutter Head (r/min) }\end{array}$ & $\begin{array}{c}\text { Cutter Opening } \\
\text { Ratio (\%) }\end{array}$ & $\begin{array}{c}\text { Closure } \\
\text { Number of } \\
\text { Cutters }\end{array}$ & $\begin{array}{c}\text { Diameter of Shield } \\
(\mathrm{mm})\end{array}$ \\
\hline Value & 80 & 3.55 & 36 & 4 \\
\hline $\begin{array}{c}\text { Length of Main } \\
\text { Machine (mm) }\end{array}$ & $\begin{array}{c}\text { Diameter of } \\
\text { Segment (mm) }\end{array}$ & $\begin{array}{c}\text { Synchronous } \\
\text { Grouting Pressure } \\
\mathbf{( M P a )}\end{array}$ & $\begin{array}{c}\text { Strain Rate of } \\
\text { Grouting Layer (\%) }\end{array}$ & $\begin{array}{c}\text { Slip Softening } \\
\text { Coefficient }\end{array}$ & $\begin{array}{c}\text { Interface Friction } \\
\text { Angle }\left({ }^{\circ}\right)\end{array}$ \\
\hline 8427 & 6000 & 0.3 & 8.4 & 0.9 \\
\hline
\end{tabular}

\section{Ground Loss Effect Factors}

Ground loss $g$ is the primary cause of stratum settlement and deformation. During shield tunnel construction, the causes of ground loss include curved propulsion, shield steering adjustment, soil thrusting into the shield tail gap, head-down propulsion, head-up propulsion, and tunnel lining deformation. The ground loss can be calculated by using the Lee's equation [36].

$$
g=G_{P}+U_{p}+\omega
$$

where $G_{p}$ is physical gap, it is the gap between the outer wall of the shield shell and the outer wall of the segment. In the field, synchronous grouting is used to decrease the physical gap, but due to the hydration reaction characteristics and the water permeation loss of cement slurry, there is still a residual gap $G_{p}{ }^{\prime}$ when the physical gap $G_{p}$ is fully filled by grouting. Usually, $G_{p}{ }^{\prime}=G_{p} \times \beta_{l}, \beta_{l}$ is slurry strain rate; $U_{p}$ is the plastic deformation of shield working face during tunnel excavation. Generally, $U_{p}=0$ when the EPB shield is used; $\omega$ is the additional ground loss induced by shield rectification, head-up propulsion, head-down propulsion and the soil consolidation in the tunneling disturbance zone. $\omega$ can be assumed to be 0 because the working face thrust of shield is equal to the soil pressure during most of the time.

\subsection{Displacement Solution}

Based on the Verruijt analytical formula [34,35], considering quantify ground loss with non-equivalent radial displacement, Loganathan [21] put forward a method for estimating stratum displacement caused by ground loss in undrained clays; the formula is as shown in Equation (2).

$$
\left\{\begin{array}{c}
S_{z}=R^{2}\left\{-\frac{z-H}{x^{2}+(z-H)^{2}}+(3-4 \mu) \frac{z+H}{x^{2}+(z+H)^{2}}-\frac{2 z\left[x^{2}-(z+H)^{2}\right]}{\left[x^{2}+(z+H)^{2}\right]^{2}}\right\} \times \varepsilon_{x, z} \\
S_{x}=-R^{2} x\left\{\frac{1}{x^{2}+(z-H)^{2}}+\frac{\left(3-4 \mu_{u}\right)}{x^{2}+(z+H)^{2}}-\frac{4 z(z+H)}{\left[x^{2}+(z+H)^{2}\right]^{2}}\right\} \times \varepsilon_{x, z}
\end{array}\right.
$$


where $R$ is tunnel external radius; $H$ is burial depth of tunnel center; $\mu$ is Poisson's ratio of soil; $\varepsilon_{x, z}$ is the parameter of non-equivalent radial displacement, fitting by exponential function based on measured data, which can be expressed as Equation (3).

$$
\varepsilon_{x, z}=\frac{4 g R+g^{2}}{4 R^{2}} \exp \left\{-\left|\frac{1.38 x^{2}}{(H+R)^{2}}+\frac{0.69 z^{2}}{H^{2}}\right|\right\}
$$

Considering that the displacement solution caused by ground loss derived by Loganathan is a two-dimensional solution, which is often a three-dimensional problem in actual engineering, it is necessary to extend the two-dimensional displacement solution to three-dimensional. The three-dimensional ground loss parameter $\varepsilon_{x, z, y}$ can be extracted from the Sagaseta' solution [20].

Sagaseta deduced the expression of ground displacement caused by tunnel construction by using the mirror source-sink method.

$$
\left\{\begin{array}{l}
S_{x 0}=-\frac{v_{\text {loss }}}{2 \pi} \frac{x}{x^{2}+H^{2}}\left[1+\frac{y}{\left(x^{2}+y^{2}+H^{2}\right)^{\frac{1}{2}}}\right] \\
S_{y 0}=\frac{v_{\text {loss }}}{2 \pi} \frac{1}{\left(x^{2}+y^{2}+H^{2}\right)^{\frac{1}{2}}} \\
S_{z 0}=\frac{v_{\text {loss }}}{2 \pi} \frac{H}{x^{2}+H^{2}}\left[1+\frac{y}{\left(x^{2}+y^{2}+H^{2}\right)^{\frac{1}{2}}}\right] \\
S_{x 0}(y \rightarrow \infty)=-\frac{v_{\text {loss }}}{\pi} \frac{x}{x^{2}+H^{2}} \\
S_{z 0}(y \rightarrow \infty)=\frac{v_{\text {loss }}}{\pi} \frac{H}{x^{2}+H^{2}}
\end{array}\right.
$$

where $V_{\text {loss }}$ is ground loss. From Equation (4) it can be found:

$$
\left\{\begin{array}{l}
S_{x 0}(y)=S_{x 0}(y \rightarrow \infty) \times \frac{1}{2} \times\left[1+\frac{y}{\left(x^{2}+y^{2}+H^{2}\right)^{\frac{1}{2}}}\right] \\
S_{z 0}(y)=S_{z 0}(y \rightarrow \infty) \times \frac{1}{2} \times\left[1+\frac{y}{\left(x^{2}+y^{2}+H^{2}\right)^{\frac{1}{2}}}\right]
\end{array}\right.
$$

Equation (5) shows that the distribution of stratum displacement caused by shield construction (ground loss) along the $\mathrm{Y}$ axis satisfies the law of $\frac{1}{2} \times\left[1+y /\left(x^{2}+y^{2}+z^{2}\right)^{\frac{1}{2}}\right]$. Therefore, based on this law, the Loganathan's solution is extended to the three-dimensional. It is noted that the coordinate system adopted in this paper is different from that used in the Sagaseta's solution, so the distribution law should be revised, and its expression is as Equation (6):

$$
\varepsilon_{y}=\frac{1}{2} \times\left[1-\frac{y}{\left(x^{2}+y^{2}+H^{2}\right)^{\frac{1}{2}}}\right]
$$

The plane ground loss parameter $\varepsilon_{x, z}$ is extended to three-dimensional parameter $\varepsilon_{x, z, y}$ which can be seen as Equation (7). Then, three-dimensional stratum displacement solution, Equation (8) can be obtained by replacing $\varepsilon_{x, z}$ in Equation (2).

$$
\begin{gathered}
\varepsilon_{x, y, x}=\varepsilon_{y} \times \varepsilon_{x, z}=\left[1-\frac{y}{\left(x^{2}+y^{2}+H^{2}\right)^{\frac{1}{2}}}\right] \times \frac{4 g R+g^{2}}{8 R^{2}} \exp \left\{-\left|\frac{1.38 x^{2}}{(H+R)^{2}}+\frac{0.69 z^{2}}{H^{2}}\right|\right\} \\
\left\{\begin{array}{l}
S_{z}=R^{2}\left\{-\frac{z-H}{x^{2}+(z-H)^{2}}+(3-4 \mu) \frac{z+H}{x^{2}+(z+H)^{2}}-\frac{2 z\left[x^{2}-(z+H)^{2}\right]}{\left[x^{2}+(z+H)^{2}\right]^{2}}\right\} \times \varepsilon_{x, y, z} \\
S_{x}=-R^{2} x\left\{\frac{1}{x^{2}+(z-H)^{2}}+\frac{(3-4 \mu)}{x^{2}+(z+H)^{2}}-\frac{4 z(z+H)}{\left[x^{2}+(z+H)^{2}\right]^{2}}\right\} \times \varepsilon_{x, y, z}
\end{array}\right.
\end{gathered}
$$




\subsection{Quantitative Analysis}

Ground loss $g$ and several parameters of Table 1 can be brought into Equation (8) to calculate ground loss displacement, and the counter map of ground settlement are shown in Figure 2. As we can see it, ground settlement at 4.5 D (D for diameter of tunnel) behind shield tail is stable to maximum $10.51 \mathrm{~mm}$, and its value at $4.5 \mathrm{D}$ in front of shield tail is only $10 \%$ of maximum. Therefore, it can be considered that the influence range of ground loss is within $4.5 \mathrm{D}$ behind and in front of shield tail. As for deep soil layer, when the vertical distance from tunnel vault is greater than $0.5 \mathrm{D}$, the settlement has little changes. However, while it is less than $0.5 \mathrm{D}$, the settlement increases rapidly, as shown in Figure $3 \mathrm{a}$. This is because that with the redistribution of stress, a pressure arch will be formed around the tunnel. The soil in the arch is a loosening zone, which has a greater displacement, and the soil out of the arch tends to be stable. As we can see from Figure 3b, horizontal displacement of deep soil is mainly distributed in $1 \mathrm{D}$ from the bottom of the tunnel.

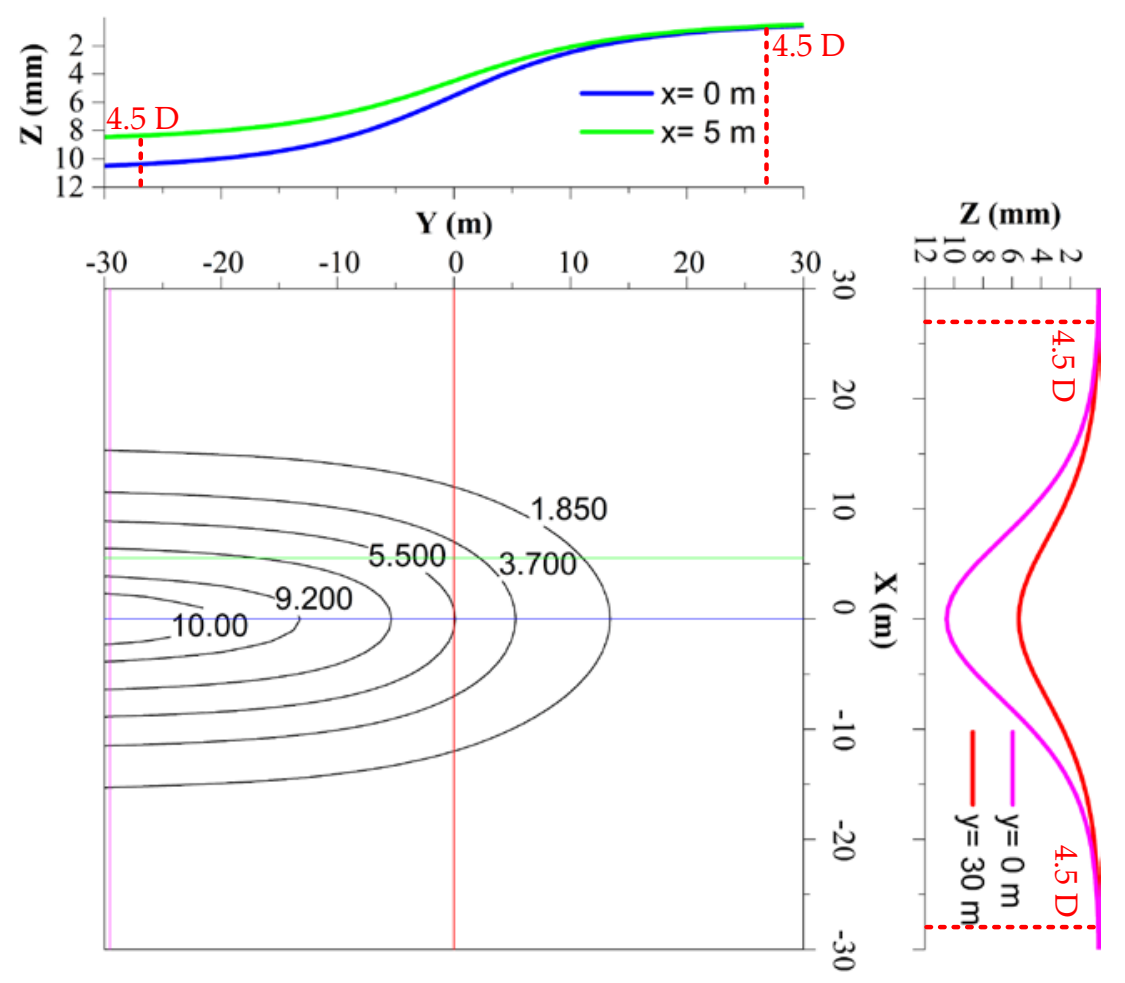

Figure 2. Counter map of ground settlement.

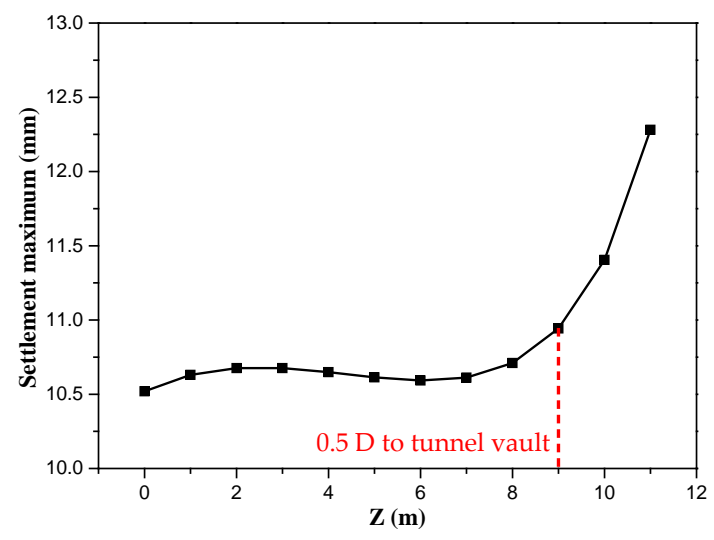

(a)

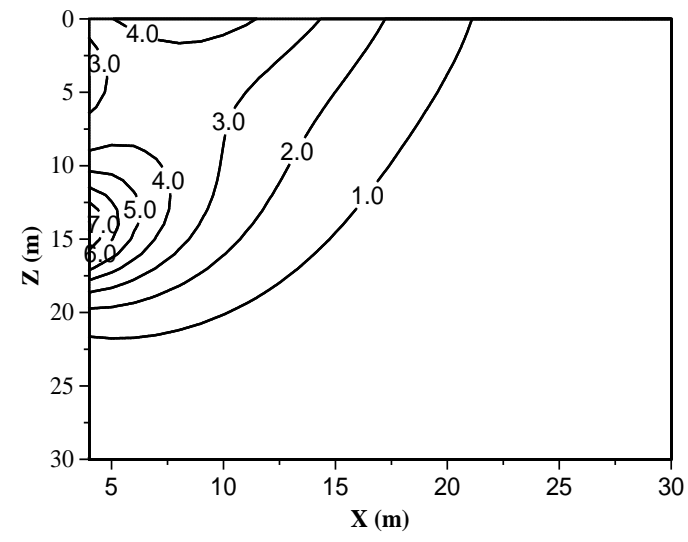

(b)

Figure 3. Displacement of stratum: (a) Variation curve of settlement maximum; (b) Counter map of horizontal displacement. 


\section{Mechanical Effect Factors}

The shield machine has a complex mechanical interaction with the surrounding stratum when shield tunnel constructs. Based on the difference of sources and action modes, these mechanical effect factors can be divided into following categories, as Figure 4: Friction $f_{d}$ between the shield working face and the soil; Additional frontal thrust $q$ on the shield working face; Shell Friction $f_{s}$ between the shield and the soil; Radial pressure $p$ generated by synchronous grouting in shield tail gap.

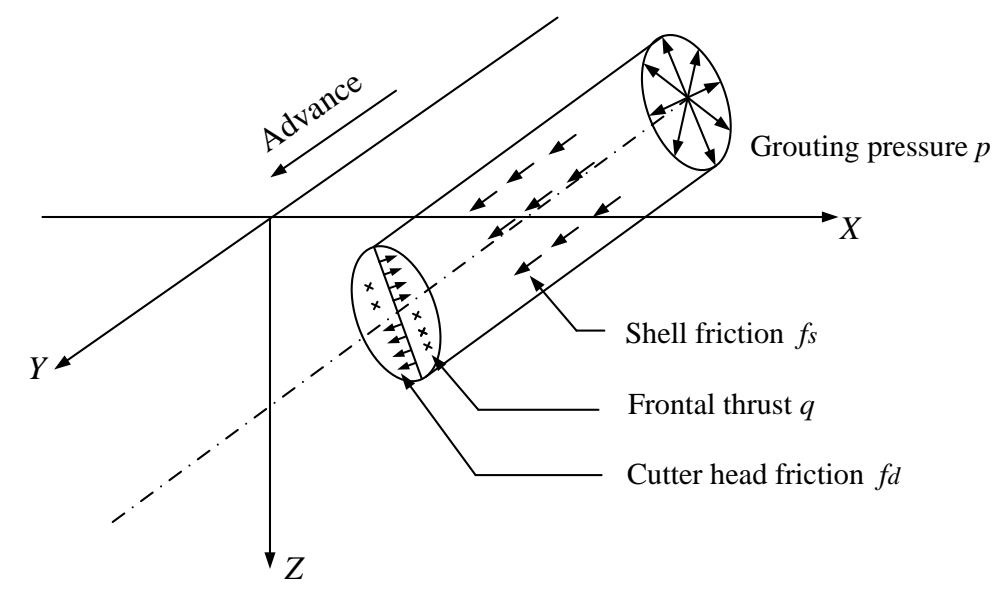

Figure 4. Four mechanical effect factors.

\subsection{Mindlin's Solutions}

The displacement caused by point load at any point can be solved by using Mindlin theoretical solution in the elastic half-space shown in Figure 5 [25]. The above four categories of force can be decomposed into vertical and horizontal forces, then brought into Mindlin solution to calculate.

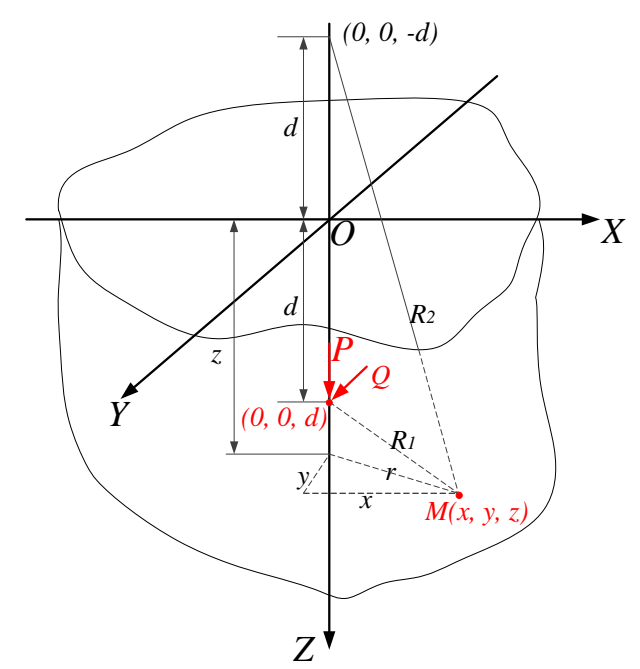

Figure 5. Mindlin model. Where $M(x, y, z)$ is any point in the infinite half space; $P$ is a vertical concentrated load; $Q$ is a horizontal concentrated load; $d$ is the burial depth of concentrated load; $R_{1}=\sqrt{r^{2}+(z-d)^{2}} ; R_{2}=\sqrt{r^{2}+(z+d)^{2}} ; r=\sqrt{x^{2}+y^{2}}$. 
When there is a vertical concentrated load $P$ at burial depth $d$, then the displacement $S_{x(y), V}$ of $\mathrm{x}(\mathrm{y})$ direction and the displacement $S_{z, V}$ of $z$ direction at any point $M(x, y, z)$ in space induced by the load $P$ can be expressed as Equation (9):

$$
\left\{\begin{array}{l}
S x(y), V=\frac{P x(y)}{16 \pi G(1-\mu)}\left[\frac{z-d}{R_{1}^{3}}+\frac{(3-4 \mu)(z-d)}{R_{2}^{3}}-\frac{4(1-\mu)(1-2 \mu)}{R_{2}\left(R_{2}+z+d\right)}+\frac{6 d z(z+d)}{R_{2}^{5}}\right] \\
S z, V=\frac{P}{16 \pi G(1-\mu)}\left[\frac{3-4 \mu}{R_{1}}+\frac{8(1-\mu)^{2}-(3-4 \mu)}{R_{2}}+\frac{(z-d)^{2}}{R_{1}^{3}}+\frac{(3-4 \mu)(z+d)^{2}-2 d z}{R_{2}^{3}}+\frac{6 d z(z+d)^{2}}{R_{2}^{5}}\right]
\end{array}\right.
$$

where $\mu$ is Poisson's ratio; $G$ is soil shear modulus.

When there is a horizontal concentrated load $Q$ parallel to $Y$ axis, pointing in the positive direction of the $\mathrm{Y}$ axis, then the displacement $S_{x, H}$ of $\mathrm{x}$ direction, $S_{y, H}$ of $\mathrm{y}, S_{z, H}$ of $\mathrm{z}$ at any point $M(x, y, z)$ in space induced by the load $Q$ can be expressed as Equation (10). While the horizontal concentrated load $Q$ parallel to $X$ axis, due to the symmetry of $\mathrm{x}$ and $\mathrm{y}$, it only needs to exchange $\mathrm{x}$ and $\mathrm{y}$ in Equation (10).

$$
\left\{\begin{array}{l}
S_{x, H}=\frac{P x y}{16 \pi G(1-\mu)}\left[\frac{1}{R_{1}^{3}}+\frac{3-4 \mu}{R_{2}^{3}}-\frac{6 d z}{R_{2}^{5}}-\frac{4(1-\mu)(1-2 \mu)}{R_{2}\left(R_{2}+z+d\right)^{2}}\right. \\
S_{y, H}=\frac{P}{16 \pi G(1-\mu)}\left[\frac{3-4 \mu}{R_{1}}+\frac{1}{R_{2}}+\frac{y^{2}}{R_{1}^{3}}+\frac{(3-4 \mu) y^{2}}{R_{2}^{3}}+\frac{2 d z}{R_{2}^{3}}\left(1-\frac{3 y^{2}}{R_{2}^{3}}\right)+\frac{4(1-\mu)(1-2 \mu)}{R_{2}+z+d}\left(1-\frac{y^{2}}{R_{2}\left(R_{2}+z+d\right)}\right)\right] \\
S_{z, H}=\frac{P y}{16 \pi G(1-\mu)}\left[\frac{z-d}{R_{1}^{3}}+\frac{(3-4 \mu)(z-d)}{R_{2}^{3}}+\frac{4(1-\mu)(1-2 \mu)}{R_{2}\left(R_{2}+z+d\right)}-\frac{6 d z(z+d)}{R_{2}^{5}}\right]
\end{array}\right.
$$

Due to the location of load in Mindlin solution is at $\mathrm{z}$ axis, the coordinate of the formula above should be transformed to use when the location of load is at any point. The global coordinate system is xyz, let the local coordinate system be uvw and coordinate origin be $O^{\prime}(m, n, k)$, shown in Figure 6 . When coordinate is transformed, xyz are replaced by uvw, then let $u=x-m, v=y-n, w=z-k$.

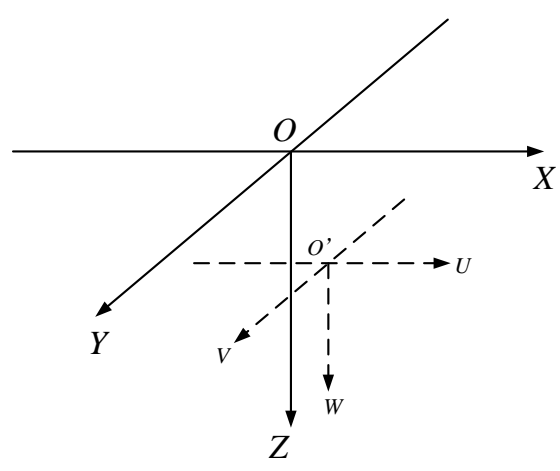

Figure 6. Coordinate transformation.

\subsection{Quantitative Analysis of Additional Thrust $q$}

When the shield machine advances, the whole machine is close to equilibrium state. However, large additional stresses still occur in the front of the cutter head, especially while plate-type panel cutter head with a small opening ratio is adopted. Wang built an extrusion model of cutter head and deduced the expression of additional thrust $q$ based on the field monitoring data, as shown in Equation (11) [37].

$$
q=\frac{10.13(1-\mu) E_{u} \pi v(1-\xi)^{2}}{(1+\mu)(3-4 \mu) D k \omega}+\Delta p^{\prime}
$$

where $E_{u}$ is undrained elastic modulus; $v$ is shield tunneling speed; $\xi$ is cutter opening ratio; $D$ is diameter of shield; $k$ is closure number of cutters; $\omega$ is angular velocity of cutter head; $\Delta p^{\prime}$ is extrusion pressure of cutters, generally takes $10-25 \mathrm{kPa}$.

Based on Equation (11) and parameters of Table 2, the additional thrust $q$ is $280 \mathrm{kPa}$. This is similar to the measured value in previous studies, which is much larger than the $20-30 \mathrm{kPa}$ generally 
considered. The additional thrust $q$ is unit surface load parallel to $\mathrm{Y}$ axis. Based on the integral region in Figure 7 and Equation (10), let $m=\rho \cos \theta, n=0, k=0$, depth of action of load element $d=H-\rho \sin$ $\theta$, stratum displacement induced by additional thrust $q$ can be obtained.

$$
\left\{\begin{array}{c}
S_{x, H}^{y, q}=\int_{0}^{R} \int_{0}^{2 \pi} q \rho d \rho d \theta \frac{(x-\rho \cos \theta) y}{16 \pi G(1-\mu)}\left[\begin{array}{c}
\frac{1}{R_{1}^{3}}+\frac{3-4 \mu}{R_{2}^{3}}-\frac{6(H-\rho \sin \theta) z}{R_{2}^{5}} \\
-\frac{4(1-\mu)(1-2 \mu)^{2}}{R_{2}\left(R_{2}+z+(H-\rho \sin \theta)\right)^{2}}
\end{array}\right] \\
S_{z, H}^{y, q}=\int_{0}^{R} \int_{0}^{2 \pi} q \rho d \rho d \theta \frac{y}{16 \pi G(1-\mu)}\left[\begin{array}{c}
\frac{z-(H-\rho \sin \theta)}{R_{1}^{3}}+\frac{(3-4 \mu)(z-H+\rho \sin \theta)}{R_{2}^{3}} \\
+\frac{4(1-\mu)(1-2 \mu)}{R_{2}\left(R_{2}+z+H-\rho \sin \theta\right)} \\
-\frac{6(H-\rho \sin \theta) z(z+H-\rho \sin \theta)}{R_{2}^{5}}
\end{array}\right]
\end{array}\right.
$$

where $R_{1}=\sqrt{r^{2}+(z-H+\rho \sin \theta)^{2}} ; R_{2}=\sqrt{r^{2}+(z+H-\rho \sin \theta)^{2}} ; r=\sqrt{(x-\rho \cos \theta)^{2}+y^{2}} ; H$ is burial depth of tunnel center; $\mu$ is Poisson's ratio of soil; $\rho$ is the distance to the center of cutter head.

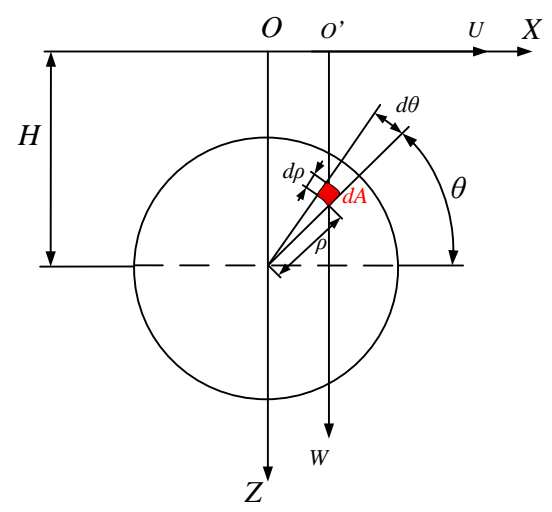

Figure 7. Integral region of $q$.

As shown in Figure 8, under the action of additional thrust $q$, ground uplifts in front of the cutter head, settlements behind the cutter head. Both reach maximum at $1 \mathrm{D}$ and tend to be stable at $4.5 \mathrm{D}$ away from the cutter head. The displacement is small by and large, for each $50 \mathrm{kPa}$ increase in $q$, the maximum displacement increases by $0.025 \mathrm{~mm}$. Figure 9 shows that the horizontal displacement caused by $q$ of the cutter head mainly appears within the depth of $1.5 \mathrm{D}$ when $\mathrm{Y}=1$.

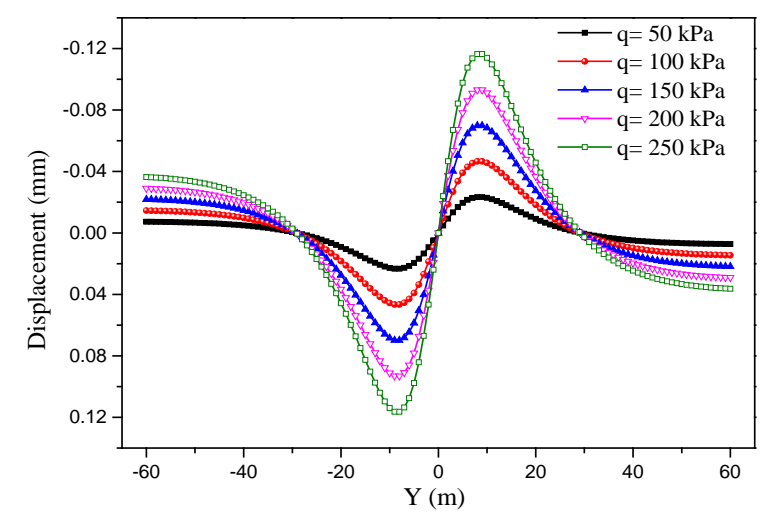

Figure 8. Longitudinal ground settlement caused by $q$. 


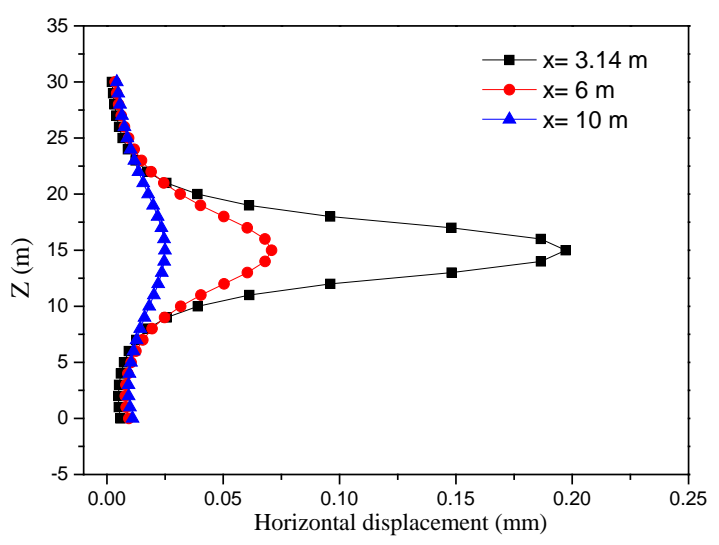

Figure 9. Horizontal displacement of stratum caused by $q$.

\subsection{Quantitative Analysis of Frictional Force $f_{d}$}

Based on the integral region shown in Figure 7, frictional force $f_{d}$ between the shield working face and the soil is expressed as Equation (12), which can be decomposed into horizontal load $f_{d H}$ and vertical load $f_{d V}$, as Equation (13). The solution of total stratum displacement can be obtained by compositing the displacements of Equation (10).

$$
\begin{gathered}
f_{d}=\left[\gamma(H-\rho \sin \theta) \frac{\mu}{1-\mu}+q\right] \times \varphi_{f} \\
\left\{\begin{array}{l}
f_{d H}=f_{d} \sin \theta \\
f_{d V}=f_{d} \cos \theta
\end{array}\right. \\
\left\{\begin{array}{l}
S_{x}^{f_{d}}=S_{x, H}^{x, f_{d H}}+S_{x, V}^{f_{d V}} \\
S_{z}^{f_{d}}=S_{z, H}^{x, f_{d H}}+S_{z, V}^{f_{V}}
\end{array}\right.
\end{gathered}
$$

where $\varphi_{f}$ is interface friction angle; $q$ is additional frontal thrust on the working face; $\rho$ is the distance to the center of cutter head; $H$ is burial depth of tunnel center; $\mu$ is Poisson's ratio of soil.

The contour map of ground settlement and horizontal displacement caused by frictional force $f_{d}$ is shown in Figure 10a,b. The distributions of displacement show good regularity. Although, as the displacement values and action range are too small (less than $0.01 \mathrm{~mm}$ ) even in deep soil quantitative analysis need not be carried out.

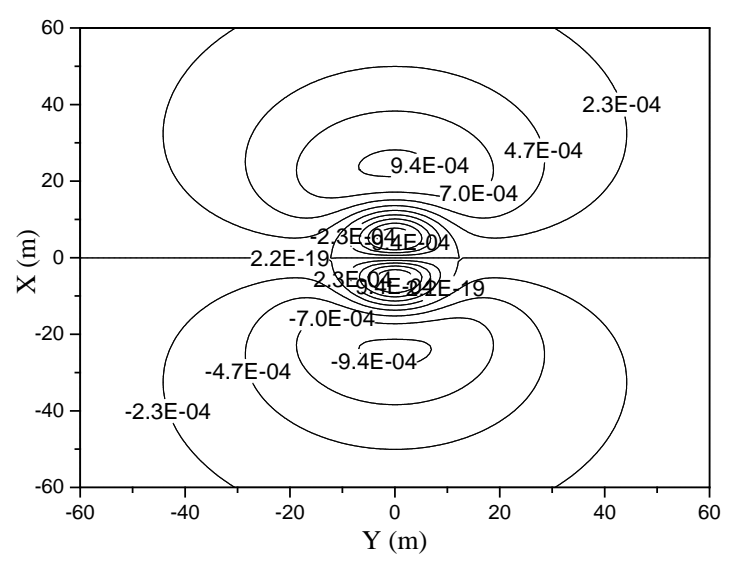

(a)

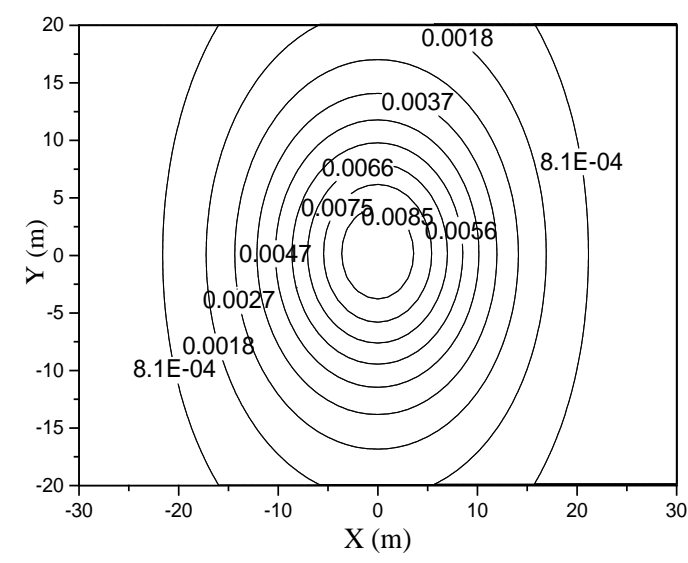

(b)

Figure 10. Ground movements caused by $f_{d}$ : (a) Settlement; (b) Horizontal displacement. 


\subsection{Quantitative Analysis of Frictional Force $f_{s}$}

As the characteristic of shell friction $f_{s}$ between the shield and the soil is like that between pile and soil, slip softening phenomenon should be considered in calculation of $f_{s}$ by Equation (15) [38-40]. Based on Equations (9) and (10) and the integral region in Figure 11, the displacement of $f_{s}$ can be calculated like $f_{d}$ above.

$$
\left\{\begin{array}{c}
f_{s}=\beta_{s} \sigma_{\theta}^{\prime} \tan \delta \\
\sigma_{\theta}^{\prime}=\sigma_{V}^{\prime} \sin ^{2} \theta+\sigma_{H}^{\prime} \cos ^{2} \theta
\end{array}\right.
$$

where $\beta_{s}$ is slip softening coefficient; $\sigma_{\theta}{ }^{\prime}$ is radial stress; $\delta$ is interface friction angle; $\sigma_{V}{ }^{\prime}$ is vertical stress; $\sigma_{H}{ }^{\prime}$ is horizontal stress.

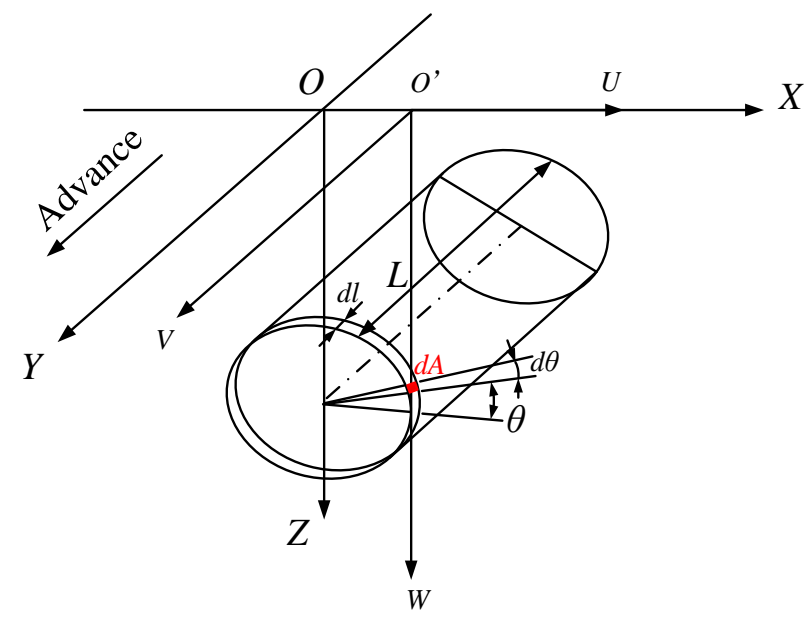

Figure 11. Integral region of $f_{s}$.

As we can see from Figure 12a,b, the ground settlement is symmetrically distributed along the $Y$ axis, ground uplifts in front of the cutter head, settlements behind the cutter head. The horizontal displacement is symmetrically distributed along the diagonal line of $\mathrm{X}$ axis and $\mathrm{Y}$ axis.

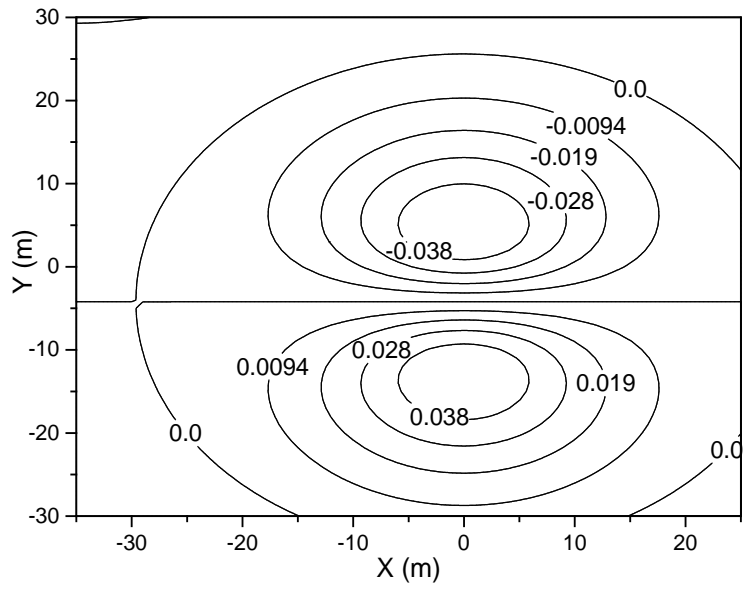

(a)

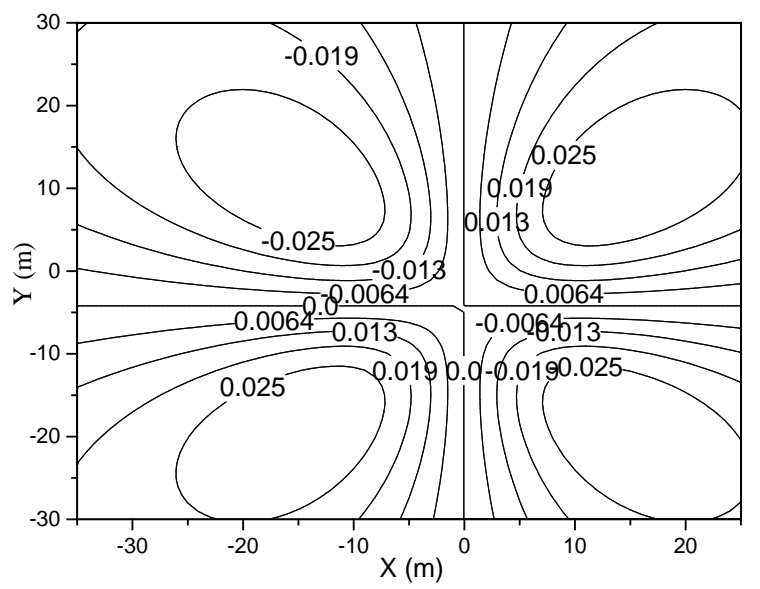

(b)

Figure 12. Ground movements caused by $f_{s}$ : (a) Settlement; (b) Horizontal displacement.

\subsection{Quantitative Analysis of Synchronous Grouting Pressure p}

Synchronized grouting at the shield tail can fill the shield tail gap in time and reduce ground loss, but on the other hand, the grouting will extrude the surrounding soil. The extrusion action can be obvious with poor water permeability and high grouting pressure, which may cause stratum uplift. 
In practice, the distribution pattern of synchronous grouting pressure is complex. In order to simplify the calculation, the following assumptions are made: the grouting pressure distributes uniformly in the circumference; little slurry diffuses into surrounding stratum in a short time, that is, the force on stratum is the same as grouting pressure; the longitudinal length of grouting is taken as 1 $\mathrm{m}$ [41]. Based on Equations (9) and (10) and the integral region in Figure 13, the displacement of $p$ can be calculated. As we can see from Figures 14 and 15, the displacement values and distribution range are small. It is worth noting that ground uplift increases significantly with the increase of grouting pressure in Figure 16, so grouting pressure needs to be selected reasonably.

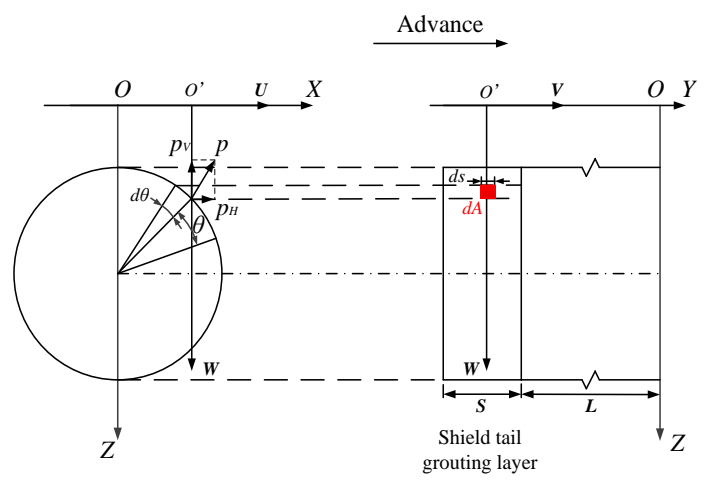

Figure 13. Integral region of $p$.

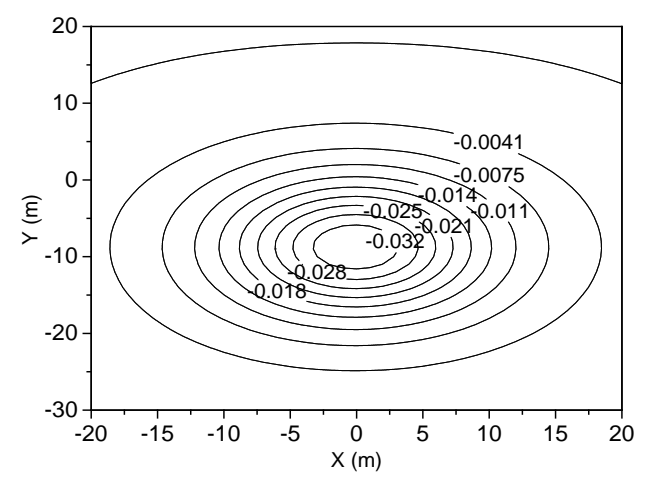

Figure 14. Ground uplift caused by $p$.

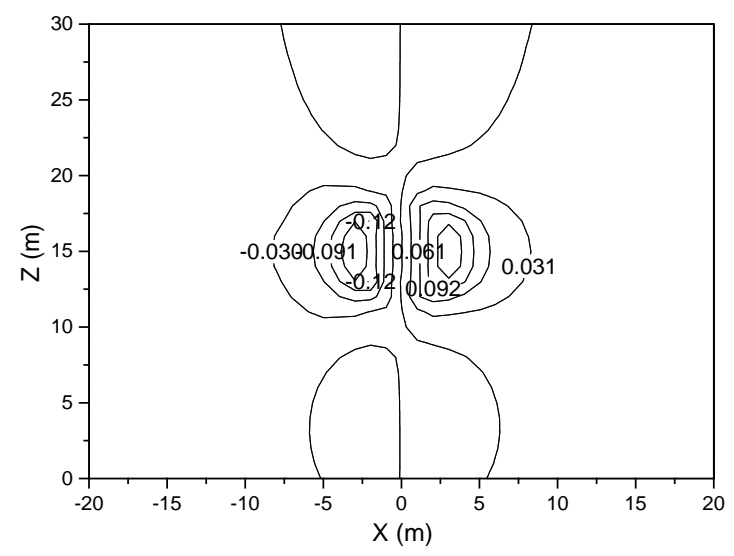

Figure 15. Horizontal displacement of stratum caused by $p$. 


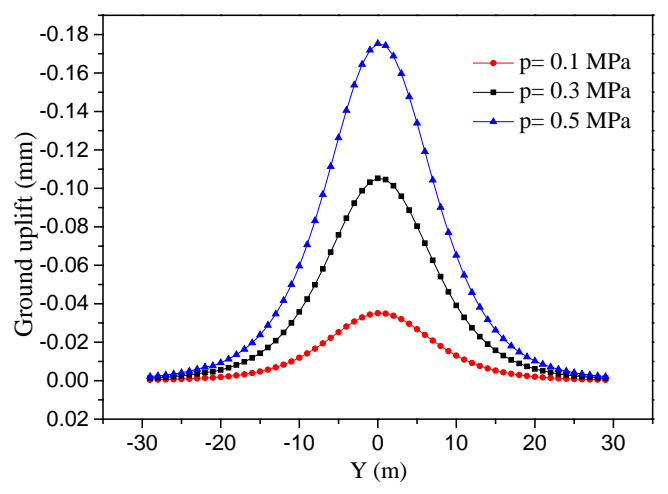

Figure 16. Ground uplift of different $p$.

\section{Verification by Field Monitoring Data}

The stratum displacements induced by various effect factors and total displacement are shown in Table 3. The effect ratio of ground loss is over $95 \%$, which plays a decisive role. The ratios to total of frictional force $f_{d}$ and $f_{s}$ are much less than $1 \%$; they are too small to be considered. The ratios of additional thrust $q$ and synchronous grouting pressure $p$ are a little larger, but are no more than $3 \%$. As shown in Figures 8 and 16, the variations of these two factors make some small quantitative changes, but no qualitative differences. It shows that this conclusion has good universality for different working conditions. The total ground settlement is compared with field monitoring data in Figure 17. From this, we can see that there are some differences between them. For example, the calculating settlement maximum is 10.25 $\mathrm{mm}$, while monitoring data is $9.7 \mathrm{~mm}$. The difference rate is $5.3 \%$, which belongs to acceptable error range. What is more, they have the same trend and the difference is stable. This is because that the elastic model is adopted in this paper, but in practice with the redistribution of stress, a pressure arch will be formed around the tunnel. The soil out of the arch is prevented from entering the loosening zone, which cause the field monitoring data to be slightly smaller than theoretical calculation result.

Table 3. The displacements induced by various effect factors.

\begin{tabular}{ccccc}
\hline Effect Factors & $\begin{array}{c}\text { Ground Settlement } \\
\text { Maximum }(\mathbf{m m})\end{array}$ & Ratio to Total & $\begin{array}{c}\text { Horizontal Displacement } \\
\text { in Stratum }(\mathbf{m m})\end{array}$ & Ratio to Total \\
\hline$q$ & -0.12 & 0.01 & 0.20 & 0.03 \\
$f_{d}$ & $<0.01$ & $<0.01$ & 0.04 & $<0.01$ \\
$f_{S}$ & \pm 0.04 & $<0.01$ & 0.03 & 0.01 \\
$p$ & -0.18 & 0.02 & 7.01 & 0.95 \\
\hline Ground loss & 10.51 & 1.02 & 7.67 & 1.00 \\
\hline total & 10.25 & 1.00 & & \\
\hline
\end{tabular}

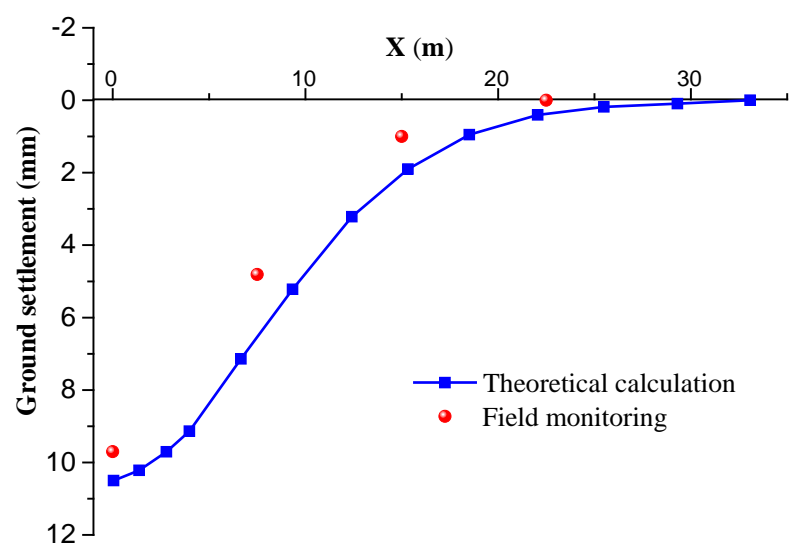

Figure 17. Total calculating displacement and field monitoring data. 


\section{Conclusions}

In order to relieve the increasing ground traffic pressure in the process of urbanization in China, it is inevitable to build more metro lines. The evaluation and control of the stratum displacement is a prominent problem during shield construction of city metro engineers. Based on the engineering project of an interval tunnel between Shizishan Station and Chuanshi Station in Chengdu Metro Line 7, China, this paper analyzed the action mechanism of stratum displacement induced by shield tunneling, and divided effect factors into two categories: ground loss factors and mechanical factors. Through the quantitative analysis of the effect factors, the following conclusions can be drawn:

(1). The calculation results of this paper are applicable for shield tunneling in urban soft soil layer, but the calculation methods and thoughts have a good universality for different working conditions, it just needs necessary parameter adjustments. Combining the advantages of Loganathan method and mirror source-sink method, the three-dimensional displacement induced by ground loss are calculated. Based on the elastic half-space Mindlin model, the displacement at any point induced by four mechanical effect factors through coordinate transformation and different integral region is deduced. The total displacement is the sum of the two, which is verified by field monitoring data. The difference is stable and the difference rate is about $5.3 \%$. This is because that the elastic model is adopted in this paper, but in practice with the redistribution of stress, a pressure arch will be formed around the tunnel. The soil out of the arch is prevented from entering the loosening zone, which causes the field monitoring data to be slightly smaller than theoretical calculation result. It is a methodological flaw, not a statistical one, and needs to be solved in future.

(2). The displacement induced by ground loss is over $95 \%$ of the total displacement, which plays a decisive role. The key to controlling stratum disturbance is decreasing the ground loss. When the outer diameter of shield and segment is determined, the most effective measure is decreasing the strain of grouting layer. As the stratum uplift caused by grouting pressure is much smaller than the settlement caused by grouting layer strain, the grouting pressure or grouting volume can be increased appropriately to ensure the grouting filling rate.

(3). The ratio of displacement caused by mechanical effect factors to total displacement is too small (less than 5\%), even far less than the error caused by various simplified assumptions in theoretical calculation. In practice, this part of the displacement cannot be separated from the total displacement, it is difficult to verify its accuracy and validity by numerical simulation or field monitoring. Therefore, it is suggested that in calculation, the mechanical effect factors can be neglected as appropriate, and only the displacement caused by ground loss is considered, which can not only reduce the computational complexity and make it easy to use, but also can meet the requirements of engineering application accuracy.

Author Contributions: Y.Z. wrote the article; L.C. provided the parameters of project; H.Z. carried out the calculations and analyzed the calculation results; P.T. processed the field data; S.C. offered some useful suggestions for the preparation.

Funding: The study was supported by the National Natural Science Foundation of China (NSFC) under Grant No. 51508037.

Acknowledgments: We also highly appreciate the contribution of data collection from China Railway No. 9 Group Co., Ltd. Finally, the authors would like to thank reviewers for useful comments and editors for improving the manuscript.

Conflicts of Interest: The authors declare no conflict of interest.

\section{References}

1. Zhang, H.; Chen, L.; Zhu, Y.; Zhou, Z.; Chen, S. Stress Field Distribution and Deformation Law of Large Deformation Tunnel Excavation in Soft Rock Mass. Appl. Sci. 2019, 9, 865. [CrossRef]

2. Zhu, Y.; Chen, L.; Zhang, H.; Zhou, Z.; Chen, S. Physical and Mechanical Characteristics of Soft Rock Tunnel and the Effect of Excavation on Supporting Structure. Appl. Sci. 2019, 9, 1517. [CrossRef] 
3. Zeng, Y.H.; Liu, K.; Fang, Y.; Zhang, X.F.; Bai, Y. Fire Model Test on Temperature Field in the Rescue Station of an Extralong Railway Tunnel. Adv. Civ. Eng. 2019, 1-12. [CrossRef]

4. Zhang, H.; Chen, L.; Chen, S.; Sun, J.; Yang, J. The spatiotemporal distribution law of microseismic events and rockburst characteristics of the deeply buried tunnel group. Energies 2018, 11, 3257. [CrossRef]

5. Lin, F.; Chen, S.G.; Zhang, H. Study on type selection of shield equipment in different geological conditions. In Green Building, Materials and Civil Engineering; CRC Press: Boca Raton, FL, USA, 2014; pp. 409-412.

6. Zhou, Z.L.; Chen, S.G.; Li, Y.S. Research on predicting and distribution of stratum displacement of double-tube parallel shield tunnel. J. Highw. Transp. Res. Dev. 2015, 32, 109-117.

7. Zou, J.F.; Qian, Z.H.; Xiang, X.H.; Chen, G.H. Face Stability of a tunnel excavated in saturated nonhomogeneous soils. Tunn. Undergr. Space Technol. 2019, 83, 1-17. [CrossRef]

8. Zhang, H.; Chen, S.G.; Deng, X.F. Analysis of the influence of shield driving parameters on ground settlements. Mod. Tunn. Tech. 2010, 47, 48-53.

9. Liao, S.M.; Liu, J.H.; Wang, R.L.; Li, Z.M. Shield tunneling and environment protection in Shanghai soft ground. Tunn. Undergr. Space Technol. 2009, 24, 454-465. [CrossRef]

10. Xie, X.Y.; Yang, Y.B.; Mei, J. Analysis of ground surface settlement induced by the construction of a large-diameter shield-driven tunnel in Shanghai, China. Tunn. Undergr. Space Technol. 2016, 51, 120-132. [CrossRef]

11. Zhang, H.; Chen, S.G.; Tan, X.R. Research on the mechanical behavior of a segment of a shield tunnel adjacent to a pile foundation. Mod. Tunn. Tech. 2012, 49, 101-107.

12. Zhang, H.; Chen, S.G.; Deng, X.F. Analysis on influence of shield tunneling on ground and bridge pile. Chin. J. Underg. Sp. Eng. 2011, 7, 552-557.

13. Peck, R.B. Deep Excavations and tunnelling in soft ground. In Proceedings of the 7th International Conference on Soil Mechanics and Foundation Engineering, Mexico City, Mexico, 25-29 August 1969; Balkema A A: Rotterdam, The Netherlands, 1969; pp. 225-290.

14. Celestino, T.B.; Gomes, R.A.M.; Bortolucci, A.A. Errors in group distortions due to settlement trough adjustment. Tunn. Undergr. Space Technol. 2000, 15, 97-100. [CrossRef]

15. Vorster, T.E.B.; Klar, A.; Soga, K.; Mair, R.J. Estimating the effects of tunneling on existing pipelines. J. Geotech. Geoenviron. 2005, 131, 1399-1410. [CrossRef]

16. Attewell, P.B.; Yeates, J.; Selby, A.R. Soil Movements Induced by Tunnelling and Their Effects on Pipelines and Structures; Thomson Science and Professional: 2nd Floor Aldgate House, 33 Aldgate High Street, London, UK, 1986.

17. Osman, A.S.; Bolton, M.D.; Mair, R.J. Predicting 2D ground movement around tunnels in undrained clay. Geotech 2006, 56, 597-604. [CrossRef]

18. New, B.M.; O'Reilly, M.P. Tunneling-induced ground movements, predicting their magnitude and effects. In Proceedings of the 4th Conference on Ground Movements and Structures; Pentech Press: London, UK, 1992; pp. 671-697.

19. O' Reilly, M.P.; New, B.M. Settlement above tunnels in the United Kingdom their magnitude and prediction. In Proceedings of the Tunneling' 82 Symposium, London, UK, 7-11 June 1982; pp. 173-181.

20. Sagaseta, C. Analysis of undrained soil deformation due to ground loss. Geotechnique 1987, 37, $301-320$. [CrossRef]

21. Loganathan, N.; Poulos, H.G. Analytical prediction for tunneling-induced ground movements in clays. J. Geotech. Geoenviron. 1998, 124, 846-856. [CrossRef]

22. Federico, P.; Andrew, J.W. Ground movements due to shallow tunnels in soft ground: 1. analytical solutions. J. Geotech. Geoenviron. 2013, 140, 04013040.

23. Kung, G.T.; Juang, C.H.; Hsiao, E.C.; Hashash, Y.M. Simplified model for wall deflection and ground-surface settlement caused by braced excavation in clays. J. Geotech. Geoenviron. 2007, 133, 731-747. [CrossRef]

24. Peng, F.L.; Wang, H.L.; Tan, Y.X.; Zheng, L.; Li, Y.L. Field measurements and finite-element method simulation of a tunnel shaft constructed by pneumatic caisson method in shanghai soft ground. J. Geotech. Geoenviron. 2011, 137, 516-524. [CrossRef]

25. Chakeri, H.; Ozcelik, Y.; Unver, B. Effects of important factors on surface settlement prediction for metro tunnel excavated by EPB. Tunn. Undergr. Space Technol. 2013, 36, 14-23. [CrossRef]

26. Zhang, Z.G.; Huang, M.S. Geotechnical influence on existing subway tunnels induced by multiline tunneling in Shanghai soft soil. Comput. Geotech. 2014, 56, 121-132. [CrossRef] 
27. Son, M.; Cording, E.J. Estimation of building damage due to excavation-induced ground movements. J. Geotech. Geoenviron. 2005, 131, 162-177. [CrossRef]

28. Ahmed, M.; Iskander, M. Analysis of tunneling-induced ground movements using transparent soil models. J. Geotech. Geoenviron. 2010, 137, 525-535. [CrossRef]

29. Mindlin, R.D. Force at a point in the interior of a semiinfinite solid. Physics 1936, 7, 195-202. [CrossRef]

30. Huang, M.S.; Zhang, C.R.; Li, Z. A simplified analysis method for the influence of tunneling on grouped piles. Tunn. Undergr. Space Technol. 2009, 24, 410-422. [CrossRef]

31. Zhang, Z.G.; Huang, M.S.; Zhang, M.X. Theoretical prediction of ground movements induced by tunneling in multilayered soils. Tunn. Undergr. Space Technol. 2011, 26, 345-355. [CrossRef]

32. Sun, H.S.; Lei, G.H.; Ng, C.W.W. Displacements under linearly distributed pressures by extended Mindlin's equations. Comput. Geotech. 2013, 50, 143-149. [CrossRef]

33. Antonio, B. Analytical solutions for shallow tunnels in saturated ground. J. Eng. Mech. 2001, 127, 1258-1266.

34. Verruijt, A.; Booker, J.R. Surface settlements due to deformation of a tunnel in an elastic half plane. Geotechnique 1996, 46, 753-756. [CrossRef]

35. Verruijt, A. Deformations of an elastic half plane with a circular cavity. Int. J. Solids Struct. 1998, 35, $2795-2804$. [CrossRef]

36. Lee, K.M.; Rowe, R.K.; Lo, K.Y. Subsidence owing to tunneling I: Estimating the gap parameter. Can. Geotech. J. 1992, 29, 929-940. [CrossRef]

37. Zhang, Q.Q.; Li, S.C.; Li, L.P.; Chen, Y.J. Simplified method for settlement prediction of pile groups considering skin friction softing and end resistance hardening. Chin. J. Rock Mech. Eng. 2013, 32, 615-624.

38. Potyondy, J.G. Skin friction between various soils and construction materials. Geotechnique 1961, 11, 339-353. [CrossRef]

39. Alonso, E.E.; Josa, A.; Iedesma, A. Negative skin friction on Piles: A simplified analysis and prediction procedure. Geotechnique 1984, 34, 341-357. [CrossRef]

40. Wang, H.X. Effect of cutterhead compressing the front soil and influence of head aperture ratio on contact pressure of EPB shield to the front soil. Chin. Civ. Eng. J. 2009, 42, 113-118.

41. Li, Z.M.; Liao, S.M.; Dai, Z.R. Theoretical study on synchronous grouting filling patterns and pressure distribution of EPB shield tunnels. Chin. J. Geotech. Eng. 2010, 32, 1752-1757.

(C) 2019 by the authors. Licensee MDPI, Basel, Switzerland. This article is an open access article distributed under the terms and conditions of the Creative Commons Attribution (CC BY) license (http://creativecommons.org/licenses/by/4.0/). 